\title{
Tuberculous aortitis
}

Zakeya A. Bukhary,* Abdulrahman A. Alrajhi $\dagger$

$\mathrm{T}$

Uuberculous aortitis (TA) is a rare entity that is invariably indicative of disseminated tuberculosis. TA is associated with aneurysm formation in about half of cases. Another possible complication is perforation of adjacent structures. ${ }^{1-7}$ Both abdominal and thoracic aorta are involved with equal frequency. ${ }^{7-9}$ Fatal outcomes are frequently reported even after antituberculosis chemotherapy and surgical intervention. We present a case of tuberculous aortic aneurysm (TBAA) that underwent surgical resection and graft replacement in the bed of the infected aorta. Following an apparently successful chemotherapy, the patient died suddenly. We postulate that reactivation of the un-eradicated bacilli precipitated graft failure. Similar cases in the literature are reviewed. We propose lifelong suppressive therapy with antituberculosis agents to prevent such a catastrophic event.

\section{Case}

A 63-year-old Saudi man, known to be hypertensive, was referred from the local hospital for further management of a markedly dilated aortic arch. He had occasional chest pain, shortness of breath, and a dry cough with no hemoptysis. He reported a history of fever, night sweats, anorexia, and a weight loss of $8 \mathrm{~kg}$ over 4 months. There was no history of tuberculosis before, or contact with, patients with tuberculosis. A few months earlier, he was told that he had an aortic aneurysm, but had declined surgery. His temperature was $37.4^{\circ} \mathrm{C}$, blood pressure $120 / 80 \mathrm{~mm}$ $\mathrm{Hg}$, respiratory rate $20 / \mathrm{min}$, and his pulse rate was $100 / \mathrm{min}$. His body weight was $65 \mathrm{~kg}$. He had no lymphadenopathy or signs of heart failure. Laboratory results showed a WBC of $5.0 \times 10^{9} / \mathrm{L}$, hemoglobin $140 \mathrm{gm} /$ $\mathrm{L}$, and platelets of $123 \times 10^{9} / \mathrm{L}$. Urinalysis and renal, hepatic, lipid, and coagulation profiles were normal. Chest $\mathrm{x}$-ray revealed a huge aneurysm of the aortic arch bulging into the left lung. The descending aorta had mild-to-moderate ectasia and tortuosity. There was bilateral pleural effusion and the cardiac size was normal. Echocardiography showed a dilated aortic arch at the junction of the descending thoracic aorta and pericardial effusion. Computed tomography of the chest confirmed the huge focal dilatation of the aortic arch measuring 9 centimeters with mural thrombosis, pericardial effusion and a few calcified and enlarged mediastinal lymph nodes. Serology for human immunodeficiency virus and syphilis was non-reactive. The patient underwent surgical resection of the aneurysm and interposition of a tube graft through a posterolateral thoracotomy approach. Intra-operatively, gross examination of the aorta revealed a huge aneurysm involving the arch as well as the proximal part of the descending aorta, another aneurysm in the middle of the descending thoracic aorta, a thickened pericardium and pleural nodules. The thoracic aneurysm was replaced from the arch down to the descending aorta. Histopathology from tissues of the aortic aneurysm, pericardium, and lymph nodes showed a granulomatous disease with central necrosis suggestive of tuberculosis. All smears were negative for acid-fast bacilli. Antituberculosis chemotherapy was started on
From the *Department of Medicine, College of Medicine, Taibah University, and the + Section of Infectious Diseases, Department of Medicine, King Faisal Specialist Hospital and Research Centre, Riyadh, Saudi Arabia

Correspondence: Abdulrahman A. Alrajbi, MD Department of Medicine $M B C 46$ King Faisal Specialist Hospital and Research Centre,

P.O. Box 3354

Riyadh, 11211

Saudi Arabia

Tel: 966-1-442-7494

Fax: 966-1-442-7499

rajbi@kfshrc.edu.sa

Accepted for publication February 2005

Ann Saudi Med 2006;26(1):56-58 
Table 1. Tuberculous aortitis involving the aortic arch.

\begin{tabular}{|c|c|c|c|c|c|c|c|}
\hline Author & Year & $\begin{array}{l}\text { Number of } \\
\text { patients }\end{array}$ & $\begin{array}{l}\text { Age } \\
\text { (years) }\end{array}$ & $\begin{array}{l}\text { Clinical presentation } \\
\text { and diagnosis }\end{array}$ & Type of aortitis & $\begin{array}{l}\text { Type of } \\
\text { surgery }\end{array}$ & Outcome \\
\hline Scully ${ }^{12}$ & 1975 & 1 & 63 & $\begin{array}{l}\text { Hemoptysis, miliary } \\
\text { tuberculosis }\end{array}$ & $\begin{array}{l}\text { Isolated aortic } \\
\text { arch, true mycotic } \\
\text { aneurysm }\end{array}$ & Resection & Died after 2 days \\
\hline Efermidis $^{7}$ & 1976 & 1 & 60 & $\begin{array}{l}\text { Fever, weight } \\
\text { loss, mediastinal } \\
\text { lymphadenopathy }\end{array}$ & $\begin{array}{l}\text { Isolated aortic arch, } \\
\text { true mycotic } \\
\text { aneurysm }\end{array}$ & Resection* & $\begin{array}{l}\text { Alive and good after } 2 \text { months } \\
\text { follow up. No recurrence }\end{array}$ \\
\hline Felson ${ }^{6}$ & 1977 & 3 & $\begin{array}{l}73 \\
59 \\
63\end{array}$ & $\begin{array}{l}2 \text { miliary TB, } \\
1 \text { hemoptysis, } \\
\text { pulmonary cavity }\end{array}$ & $\begin{array}{l}\text { Isolated aortic arch, } \\
\text { true mycotic } \\
\text { aneurysm }\end{array}$ & $\begin{array}{l}2 \text { cases graft } \\
\text { replacement* } \\
1 \text { surgical } \\
\text { resection* }\end{array}$ & $\begin{array}{l}\text { Two died. First, } 2 \text { days after } \\
\text { surgery, of cardiac arrest. } \\
\text { Second, } 3 \text { weeks later, of fatal } \\
\text { hemoptysis. Third, had miliary TB } \\
\text { and graft replacement. Lived with } \\
\text { no recurrence }\end{array}$ \\
\hline Current case & & 1 & 63 & $\begin{array}{l}\text { Chest pain, pleuro- } \\
\text { pericardium, } \\
\text { disseminated TB }\end{array}$ & $\begin{array}{l}\text { Aortic arch, true } \\
\text { mycotic aneurysm } \\
\text { and descending } \\
\text { thoracic aorta }\end{array}$ & $\begin{array}{l}\text { Resection* } \\
\text { and graft } \\
\text { replacement }\end{array}$ & $\begin{array}{l}\text { Died, recurred ruptured } \\
\text { aneurysm } 13 \text { months after } \\
\text { stopping anti-TB }\end{array}$ \\
\hline
\end{tabular}

*Patients received anti-TB therapy prior to or after surgery

the first postoperative day in the form of isoniazid, rifampin, pyrazinamide, ethambutol and vitamin B6. Specimens from the tissue of the aortic aneurysm, the pericardium, the lymph nodes, the tracheal aspirates, and pleural tissue grew Mycobacterium tuberculosis sensitive to isoniazid, rifampin, pyrazinamide, and ethambutol. The subsequent course was notable for excellent tolerance and adherence to antituberculosis agents. Pyrazinamide and ethambutol were discontinued after the first two months. The patient reported general improvement in his well-being, he gained weight, and had resolution of radiological findings on subsequent imaging. Repeat computed tomography of the chest and echocardiography revealed no aortic dilatation. Isoniazid and rifampin were continued for a total of 18 months. Three months after discontinuing isoniazid and rifampin, the patient was feeling well and gained 3 further kilograms. Ten months later, the patient had sudden onset chest pain and collapsed. He had very low blood pressure in a local hospital. Immediate computed tomography of the chest showed hemothorax. The patient died soon thereafter. No post-mortem was performed.

\section{Discussion}

Before the antibiotic era, the majority of TA were diagnosed incidentally at autopsy. ${ }^{10} \mathrm{With}$ increasing clinical awareness, improved imaging and success- ful therapy early diagnosis has increased. ${ }^{8}$ Common clinical presentations include the constitutional symptoms and signs of tuberculosis with or without an aneurysmal mass effect, depending on the location. Tuberculous aortic aneurysm usually manifests as a pulsatile or palpable mass, chest pain, dysphagia, hoarsenees, abdominal pain, back pain, and if complicated, by a fistula, perforations, bleeding, and rupture. Our patient presented with a 4-month history of tuberculous symptoms of fever, night sweats, and weight loss. The chest pain and dry cough were indications for chest radiographic imaging, which led to recognition of the aortic aneurysm at the local hospital. Aneurysm with fever and clinical suspicion of tuberculosis should raise the suspicion of TA. ${ }^{3,7,10}$ We think the most likely mechanism of TA was direct extension from a nearby focus of infected lymph nodes; less likely is direct implantation on the inner vessel wall and hematogenous spread to the adventitia by the vasa vasarum..$^{7-9,11}$ Tuberculosis was not suspected in our case, preoperatively. The working diagnosis was an aortic aneurysm planned for surgical intervention. We have histopathological and microbiological confirmation of the involvement of M. tuberculosis with the aneurysm. The disease was disseminated, involving all mediastinal tissues and tracheal secretions.

TA usually involves the distal junction of the aortic arch along with the descending aorta, which is ad- 
jacent to the mediastinal structures. Involvement of the ascending aorta is rarely reported. In a few cases, involvement of the aortic arch was reported.6, 7, 12,13 Table 1 summarizes aortic arch tuberculous aortitis cases previously reported. There are about 14 cases of successful surgical resection of the tuberculous aortic aneurysm of the descending thoracic aorta. ${ }^{2,14}$ In the English literature, less than 50 cases of tuberculous aortic aneurysm were reported between 1945 and 2003. . $^{8,10,11,14-17}$

The duration of chemotherapy for disseminated tuberculosis is usually one year. For this patient, treatment was extended for 18 months because of concerns of graft infection. The extent of $M$. tuberculosis involvement in the aneurysm was so large that the newly inserted graft was basically placed where $M$. tuberculosis bacilli were abundant. However, because of a lack of previously published experience on duration of therapy, the susceptibility data of the isolate, and the excellent response to therapy, the 18month course was considered sufficient. We postulate that the sudden death of the patient indicates probable rupture of the aortic aneurysm. The finding of hemothorax on computed tomography of the chest is supportive. This could have happened after reactivation of $M$. tuberculosis bacilli and dehiscence of the graft. Graft infection and its attendant complications may appear postoperatively or may be the cause of the recurrence at the operative site even with prolonged chemotherapy. ${ }^{3,9}$ Without autopsy, the final events could never be confirmed. We would, therefore, consider lifelong suppression therapy with isoniazid after completing the treatment course. The goal is to prevent further bacillary growth at the non-viable graft material with the hope of prolonging its survival and functionality.

\section{References}

1. Bojar RM, Turner MT, Valdez S, Haskal R, McGowan K, Khabbaz KR. Homograft repair of a tuberculous pseudoanuerysm of the ascending aorta. Chest. 1998;114:1774-1776.

2. Ikezawa T, Iwatsuka Y, Naiki K, Asano M, Ikeda

$S$, Kimura A. Tuberculous pseudoaneurysm of the descending thoracic aorta: A case report and literature review of surgically treated cases. $J$ Vasc Surg. 1996;24:693-697.

3. Cargile JS 3rd, Fisher DF Jr, Burns DK, Fry WJ. Tuberculous aortitis with associated necrosis and perforation: treatment and options. $J$ Vasc Surg. 1986;4:612-615.

4. Gajaraj A, Victor S. Tuberculous aortoarteritis. Clin Radiol. 1981;32:461-466.

5. Sellers AL, Light JG, Friedman NB. Acute anuric renal failure secondary to tuberculous aortitis of the thoracic aorta. JAMA. 1976;236:1384-1385.

6. Felson B, Akers PV, Hall GS, Schreiber JT, Greene

RE, Pedrosa CS. Mycotic tuberculous aneurysm of the thoracic aorta. JAMA. 1977;237:1104-1108.

7. Efremidis SC, Lakshamanan S, Hsu JT. Tuberculous aortitis: a rare cause of mycotic aneurysm of the aorta. Am $J$ Roentgenol. 1976;127:859-861.

8. Long R, Guzman R, Greenberg H, Safneck J, Hershfield $E$. Tuberculous mycotic aneurysm of the aorta: review of published medical and surgical experience. Chest. 1999;115:522-531.

9. Munyer TP, Margulis AR. Tuberculous aortitis.

AJR Am J Roentgenol. 1981;136:1024-1026.

10. Silbergleit A, Arbulu A, Defever BA, Nedwicki EG. Tuberculous aortitis: surgical resection of ruptured abdominal false aneurysm. JAMA. 1965;193:333-335.

11. Choi JB, Yang HW, Oh SK, Yun KJ. Rupture of ascending aorta secondary to tuberculous aortitis. Ann Thorac Surg. 2003;75:1965-1967.

12. Scully RE, Galdabini JJ, McNeely BU. Case

records of the Massachusetts General hospital.
N Eng J Med. 1975;293:394-399.

13. Mally A, D'Souza C, Dwivedi S, Shatapathi P. Pulmonary tuberculosis with multiple sacular aneurysms of the aorta: a case report. Angiology. 1990;41:333-336.

14. Strnad BT, McGraw JK, Heatwole EV, Clark P. Tuberculous aneurysm of the aorta presenting with uncontrolled hypertension. J Vasc Interv Radiol. 2001;12:521-523.

15. Ohtsuka T, Kotsuka Y, Yagyu K, Furuse A, Oka $\mathrm{T}$. Tuberculous pseudoaneurysm of the thoracic aorta. Ann Thorac Surg. 1996;62:1831-1834.

16. Matsumoto A, Noguchi Y, Ishiwa N, Yamamoto $Y$, Yoshida S, Yoshida S. Tuberculous aortitis, ruptured 48 years after therapeutic implantation of synthetic balls. J Cardiovascular Surg. 2002;43:129-132.

17. Aebert H, Birnbaum DE. Tuberculous pseudoaneurysm of the aortic arch. $J$ Thorac Cardiovasc Surg. 2003;125:411-412. 